\title{
Automated snow avalanche release area delineation - validation of existing algorithms and proposition of a new object-based approach for large-scale hazard indication mapping
}

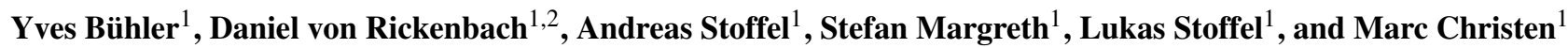 \\ ${ }^{1}$ WSL Institute for Snow and Avalanche Research SLF, Davos Dorf, 7260, Switzerland \\ ${ }^{2}$ Department of Geography, University of Zürich, Zürich, 8057, Switzerland
}

Correspondence: Yves Bühler (buehler@slf.ch)

Received: 1 May 2018 - Discussion started: 12 June 2018

Revised: 16 November 2018 - Accepted: 26 November 2018 - Published: 10 December 2018

\begin{abstract}
Snow avalanche hazard is threatening people and infrastructure in all alpine regions with seasonal or permanent snow cover around the globe. Coping with this hazard is a big challenge and during the past centuries, different strategies were developed. Today, in Switzerland, experienced avalanche engineers produce hazard maps with a very high reliability based on avalanche database information, terrain analysis, climatological data sets and numerical modeling of the flow dynamics for selected avalanche tracks that might affect settlements. However, for regions outside the considered settlement areas such area-wide hazard maps are not available mainly because of the too high cost, in Switzerland and in most mountain regions around the world. Therefore, hazard indication maps, even though they are less reliable and less detailed, are often the only spatial planning tool available. To produce meaningful and cost-effective avalanche hazard indication maps over large regions (regional to national scale), automated release area delineation has to be combined with volume estimations and state-of-the-art numerical avalanche simulations.

In this paper we validate existing potential release area (PRA) delineation algorithms, published in peer-reviewed journals, that are based on digital terrain models and their derivatives such as slope angle, aspect, roughness and curvature. For validation, we apply avalanche data from three different ski resorts in the vicinity of Davos, Switzerland, where experienced ski-patrol staff have mapped most avalanches in detail for many years. After calculating the best fit input parameters for every tested algorithm, we compare their performance based on the reference data sets. Because all tested algorithms do not provide meaningful delineation be-
\end{abstract}

tween individual PRAs, we propose a new algorithm based on object-based image analysis (OBIA). In combination with an automatic procedure to estimate the average release depth $(d 0)$, defining the avalanche release volume, this algorithm enables the numerical simulation of thousands of avalanches over large regions applying the well-established avalanche dynamics model RAMMS. We demonstrate this for the region of Davos for two hazard scenarios, frequent (10-30year return period) and extreme (100-300-year return period). This approach opens the door for large-scale avalanche hazard indication mapping in all regions where high-quality and high-resolution digital terrain models and snow data are available.

\section{Introduction}

Snow avalanches are a severe threat in alpine regions around the world, endangering people, buildings and traffic infrastructure. In Switzerland an average of 25 people die per year in avalanches, the vast majority during winter sport activities (Techel et al., 2015), and avalanches often cause infrastructure damage. In winter 1999 the total damage was more than EUR 500 million (SLF, 2000). Switzerland has longterm experience coping with avalanche hazards. These range from spatial planning measures, such as avoiding building where there is an avalanche hazard, usually achieved by trial and error over centuries up to constructional measures such as the splitting wedge at the church of Davos Frauenkirch, built in 1603 after the previous church was destroyed by a large avalanche. One of the most important measures is the 
generation of hazard maps. Such maps, the first one was already released 1953 in the Bernese Alps, are based today on avalanche database information, climatic information on extreme snowfall events, terrain analysis and numerical simulations of the avalanche dynamics. All this information is combined by experienced experts into scenarios. In Switzerland, hazard maps are based on 30-,100- and 300-year scenarios (Fig. 11a). Hazard maps show the hazard degree based on the frequency and intensity of avalanches. The elaboration of hazard maps is very demanding with respect to time and expertise. Furthermore it can only be applied to single avalanche tracks that are, in particular, endangering critical infrastructure (Gruber and Margreth, 2001). But these maps are the backbone of the Swiss avalanche mitigation strategy and are legally binding for where new infrastructure can be built and where not.

Hazard indication maps, however, are less detailed and accurate than hazard maps but can give a spatially continuous overview on avalanche hazards based on numerical simulations over large regions. Hazard indication maps are based on an extreme scenario and do not show different hazard degrees. This is particularly useful for regions with sparse avalanche database information, which is the case for most alpine regions around the world. High-spatialresolution digital terrain models (DTMs) generated from remote-sensing instruments are becoming more and more available for mountain regions (Bühler et al., 2012; Fonstad et al., 2013; ASPRS, 2001) and open the door for meaningful numerical avalanche simulations (Bühler et al., 2011) over large areas, e.g., entire valleys, states or even countries.

To perform dynamic avalanche simulations with state-ofthe-art software such as RAMMS (Christen et al., 2010) or SAMOS (Sampl and Zwinger, 2004), an accurate identification of the release areas and the release volumes is mandatory. Prerequisites for triggering a snow slab avalanche can be summarized in three categories: (1) terrain, (2) snow cover specific factors and (3) meteorological factors (Schweizer et al., 2003). In the past, different algorithms have been developed to identify potential snow avalanche release areas (PRAs) mainly based on terrain-specific parameters. So far, these algorithms to identify PRAs have never been compared and tested against a large reference data set of observed and carefully mapped avalanche release areas. Therefore, the first aim of this study is to conduct a comparison of the existing algorithms based on avalanche database information from Davos, Switzerland. Based on the findings gained from this comparison, we develop a new algorithm for automated PRA delineation and validate it at three selected test sites around Davos, Switzerland, where we have an excellent avalanche database. We constrain the reference data set to slab avalanches and exclude loose snow avalanches, which can also start at point locations in very steep terrain but usually do not mobilize masses that could be dangerous for people and infrastructure in the Alps. However, such avalanches can become more dangerous in other regions such as the Chilean Andes (Vera Valero et al., 2016).

\section{Existing algorithms}

In the past, DTM-based identification of PRAs for different types of mass movements have been developed, in particular for shallow and deep-seated landslides (Carrara, 1983; Carrara and Guzetti, 1995; van Westen et al., 2003; Singh et al., 2005; van Westen et al., 2008; Gruber et al., 2009; Pradhan and Buchroithner, 2012; Budimir et al., 2015), as well as for debris flows and rockfalls (Singh et al., 2005; Michoud et al., 2012). The most important DTM-derived parameter for landslides and rockfalls is the slope angle, which strongly determines the distribution of unstable areas (Carrara and Guzetti, 1995). In addition, aspect and curvature are also considered (Singh et al., 2005; Pradhan and Buchroithner, 2012).

Similar attempts have been made to automatically delineate snow avalanche release areas. Voellmy (1955) already stated that the terrain parameter slope angle plays a decisive role in identifying PRAs. The first automated approaches to identifying PRAs, considering different terrain parameters, began with the availability of DTMs with quite coarse resolution in the range of 25 to $30 \mathrm{~m}$ (Maggioni et al., 2002; Maggioni, 2005; Maggioni and Gruber, 2003). DTMs with higher spatial resolution ( 1 to $10 \mathrm{~m}$ ) enable the calculation of DTM derivatives such as ruggedness or curvature, which are of major importance for avalanche release (van Herwijnen and Heierli, 2009; McClung, 2001; Schweizer et al., 2003; Vontobel, 2011). Table 1 gives an overview of PRA delineation algorithms, published in peer-reviewed journals found on Web of Science, and the terrain derivatives they apply.

All listed algorithms apply the parameter slope; most apply plan curvature but only two of them also include the parameter roughness. For this study, the following three existing algorithms are compared and validated: one simple algorithm considering just the parameter slope after Voellmy (1955) as a benchmark and the two recent algorithms taking the terrain roughness into account (Bühler et al., 2013; Veitinger et al., 2016). The algorithm of Maggioni et al. (2002) was also tested but only produces meaningful results with DEM resolutions on the order of $25 \mathrm{~m}$. Furthermore, this algorithm was written in ARC Macro Language and is difficult to run with the current software. The other algorithms by Ghinoi and Chung (2005), Barbolini et al. (2011), Andres and Chueca Cia (2012), Pistocchi and Notarnicola (2013), and Chueca Cia et al. (2014) have been developed by other research groups and were not available for comparison. 
Table 1. Overview of the published avalanche release area delineation algorithms including the applied parameters. Parameters in parentheses are partially included in the algorithm.

\begin{tabular}{|c|c|c|c|c|c|c|c|c|c|c|}
\hline $\begin{array}{l}\text { Publication } \\
\text { (chronological) }\end{array}$ & Slope & $\begin{array}{c}\text { Plan } \\
\text { curvature }\end{array}$ & $\begin{array}{c}\text { Profile } \\
\text { curvature }\end{array}$ & Roughness & Aspect & Elevation & $\begin{array}{l}\text { Distance } \\
\text { to ridge }\end{array}$ & $\begin{array}{l}\text { Wind } \\
\text { shelter }\end{array}$ & $\begin{array}{c}\text { Topographic } \\
\text { wetness } \\
\text { index }\end{array}$ & Vegetation \\
\hline Voellmy (1955) & $\times$ & & & & & & & & & \\
\hline Maggioni et al. (2002) & $\times$ & $\times$ & & & $\times$ & & $\times$ & & & \\
\hline Ghinoi and Chung (2005) & $x$ & & & $(\times)$ & $x$ & $\times$ & $x$ & & & $(\times)$ \\
\hline Barbolini et al. (2011) & $\times$ & $\times$ & & & & & & & & $\times$ \\
\hline Andres and Chueca Cia (2012) & $\times$ & $\times$ & & & & $\times$ & & & & $x$ \\
\hline Pistocchi and Notarnicola (2013) & $\times$ & $x$ & $\times$ & & $\times$ & & $\times$ & & $\times$ & $\times$ \\
\hline Bühler et al. (2013) & $\times$ & $\times$ & & $\times$ & & & & & & \\
\hline Chueca Cia et al. (2014) & $\times$ & $\times$ & & & & $\times$ & & & & $\times$ \\
\hline Veitinger et al. (2016) & $\times$ & & & $\times$ & & & & $\times$ & & $\times$ \\
\hline
\end{tabular}

\section{Validation of selected existing algorithms}

\subsection{Reference data set}

For a meaningful comparison and validation of the three selected algorithms, a good reference data set is mandatory. Explicit and accurate reference data on avalanche release areas are very scarce because the release areas are remote, mostly in poorly accessible terrain. Even though some approaches exist to automatically map snow avalanches from high-spatial-resolution remote-sensing data (Bühler et al., 2009; Lato et al., 2012; Eckerstorfer et al., 2016; Korzeniowska et al., 2017), such data sets are only available for isolated time periods. Recent advances using freely available Sentinel-1 radar data succeed in mapping a part of the avalanche deposits but do not produce reliable information on release areas (Eckerstorfer et al., 2017). Therefore, the best available information on avalanche release areas still comes from manual mapping in the field.

For the region of Davos, Switzerland, the SLF maintains an event database whereby the avalanche contours and the release areas are mapped by experienced staff. This event database is considered to be one of the best reference data sets available today. The reference data set contains 5785 mapped release areas from the year 1970 until 2016. The avalanches of the extreme winter 1999 are included in the data set as well. Out of this reference data set, three test sites were deliberately chosen: Parsenn, Jakobshorn and Rinerhorn. These test sites are located in the three largest ski resorts of Davos. Consequently, these areas are surveyed more or less constantly during winter operations, and observed avalanche events, naturally and artificially triggered, are mapped by the ski patrol and included in the SLF database. We limit the test regions to the areas that are well observed from the ski resorts and exclude terrain sections where observations of avalanche are difficult. Thus, it can be assumed that, as far as possible, all potential release areas have already been mapped at least once. However, a check of the reference data set with the local ski patrol heads showed that certain release areas known to them are still not included. We also included these observations in the reference data set at the three test sites to achieve a result as complete as possible.

The test site Parsenn (Fig. 1) is the largest with an area of $7.3 \mathrm{~km}^{2}$ ranging from 2200 up to $2830 \mathrm{~m}$ a.s.l. with a mean elevation of $2460 \mathrm{~m}$ a.s.l. The mean slope angle is $25^{\circ}$. In this region we count 1382 individual manually mapped PRAs that do partly overlap. In the southern part, a small area is spared because it is not very visible from the ski area and therefore not documented well enough. The test site Jakobshorn (Fig. 1) has an area of $2 \mathrm{~km}^{2}$ and ranges from 2310 up to $2680 \mathrm{~m}$ a.s.l. with a mean elevation of $2450 \mathrm{~m}$ a.s.l. The mean slope angle is $28^{\circ}$, which is considerably steeper than Parsenn but the terrain does lack steep rock faces. We count 309 individual PRAs at Jakobshorn. The test region Rinerhorn (Fig. 1) ranges from 2200 up to $2910 \mathrm{~m}$ a.s.l. with a mean elevation of $2440 \mathrm{~m}$ a.s.l. and a mean slope angle of $29^{\circ}$. It is the steepest test region with the largest amount of rough rock face and counts 438 individual PRAs. In total we have 2129 individual PRAs at all three test sites.

\subsection{Validation methods}

The three selected algorithms subdivide the area within a certain perimeter into the two classes: PRA and no potential release area (NoPRA). The model output of these algorithms can be seen as thematic maps with the two discrete classes, PRA and NoPRA. Hence, for validation, an error matrix (Fig. 2) is calculated as it is known for the accuracy assessment of thematic mapping in remote sensing (Congalton and Green, 1999). To produce an error matrix, a reference data set is needed. Each value in the error matrix represents the total intersectional area of a specific reference class and algorithm class. For most of the state-of-the-art avalanche dynamic simulation software, PRAs are required as discrete vector objects to be able to perform dynamic avalanche simulations. Therefore, the algorithms also output the release areas as vector objects. Consequently, the area values calculated for the error matrix are square meters and not number of pixels, which would be rather common for the error matrix (Stehman and Wickham, 2011). Based on this error matrix, 


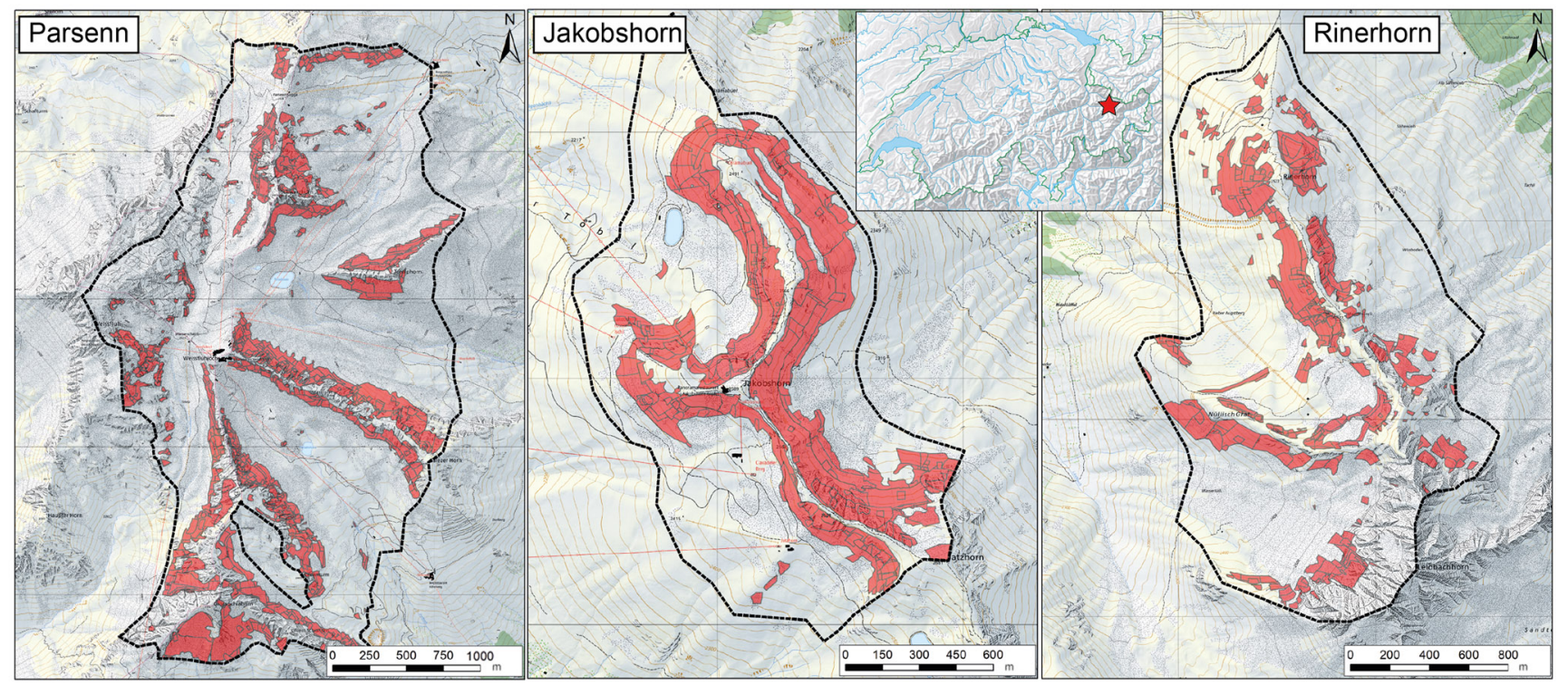

Figure 1. Reference data sets including the manually mapped avalanche release areas (red polygons) in the three test regions Parsenn, Jakobshorn and Rinerhorn. The inset indicates the location of the test region Davos within Switzerland (pixmaps@ 2018 swisstopo (5704 000 000), reproduced with the permission of swisstopo (JA100118)). Data are from Bühler and von Rickenbach (2018).

different accuracy measures can be calculated (Allouche et al., 2006).

Probability of detection $(\mathrm{POD})=\frac{a}{a+c}$

Probability of false detection $(\mathrm{POFD})=\frac{b}{b+d}$

Peirce skill score (PSS)

$$
=\mathrm{POD}-\mathrm{POFD}=\frac{a}{a+c}-\frac{b}{b+d}
$$

Overall accuracy $(\mathrm{OA})=\frac{a+d}{n}$

Heidke skill score $(\mathrm{HSS})=\frac{\mathrm{OA}-\mathrm{CA}}{1-\mathrm{CA}}$,

$$
\mathrm{CA}=\frac{(a+b \times a+c)+(c+d \times b+d)}{n^{2}}
$$

The PSS is applied as an accuracy measure to find the optimal values for the input parameters. The PSS is also known as true skill statistics (TSS) or Hanssen-Kuipers discriminant named after Hanssen and Kuipers (1965). In this paper, the PSS is scaled by a factor of 100 to enhance the interpretability and thus ranges from -100 to 100 . A PSS of 100 indicates perfect agreement, whereas values of zero or less indicate a performance not better or worse than a random classifier (Allouche et al., 2006). As aforementioned, the purpose of PRA delineation in this paper is the automated hazard indication mapping. Hazard indication maps should comprise all potential spatial occurrences of a certain hazard process (in this case snow avalanches). Therefore, the algorithm should correctly classify PRAs compared to the reference data set. But at the same time, NoPRA should also be correctly classified. The first criterium is measured by the POD and the second by the POFD. The better the algorithm the higher the POD (range: 0-100) and the lower the POFD (range: $0-100)$. These two measures are combined in the PSS. In contrast to the HSS, the PSS is independent to prevalence (Allouche et al., 2006). Prevalence stands for the different proportion of the two classes (in this case PRA and NoPRA) (Beguería, 2006). Therefore the PSS is widely applied for the validation and evaluation of predictive models in hazard assessment and risk management (Beguería, 2006). Examples for this are the validation of landslide susceptibility models (Leonarduzzi et al., 2017; Gariano et al., 2015; Frattini et al., 2010) or avalanche hazard (Purves et al., 2003). As a second overall accuracy measure we apply the HSS (Heidke, 1926), also referred to as Kappa.

\subsection{Input parameter setting}

The algorithm created by Veitinger et al. (2016) requires parametrization for snow depth, wind direction and wind direction variability. We specify no dominant wind direction as this cannot be clearly identified as the region faces different wind regimes ranging from northwest to south (Schüepp and Urfer, 1962). Furthermore, in most regions a broad hazard indication mapping scenario cannot be reliably connected to a specific wind regime. The roughness is calculated depending on the mean snow depth. Afterwards, the algorithm applies an individual fuzzy membership function to roughness and slope. Based on this multi-scale fuzzy logic approach, the al- 


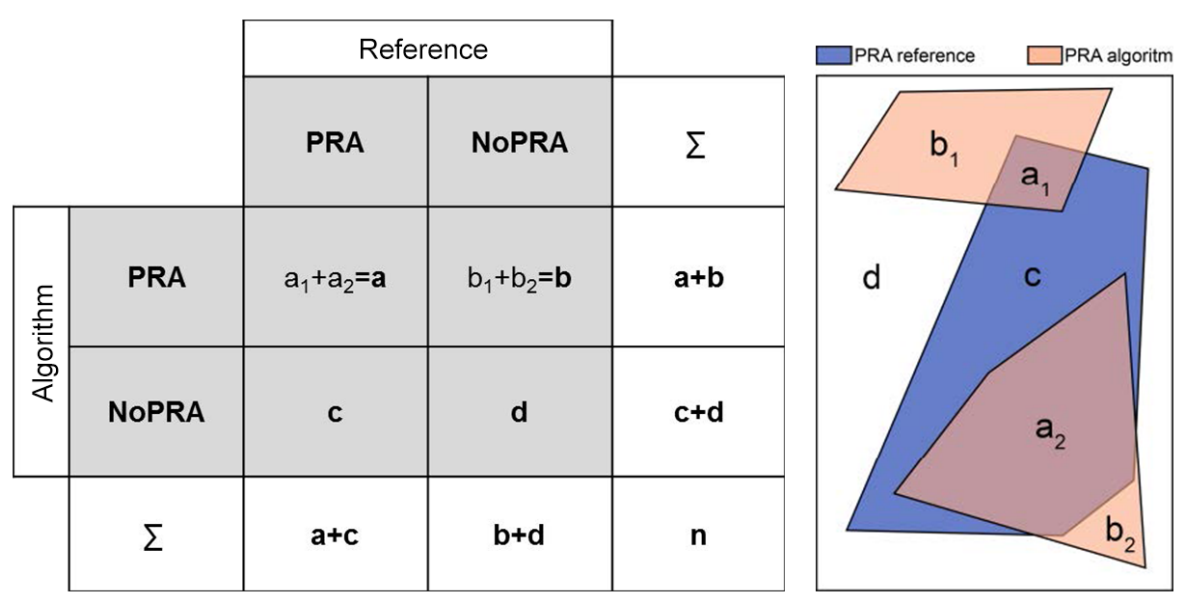

Figure 2. Schema of the applied validation measures after Congalton and Green (1999).

gorithms' output indicates the avalanche release probability in a continuous range from 0 (not probable) to 1 (highly probable). The other algorithms apply Boolean classifiers and thus these outputs exhibit the two discrete classes 0 (NoPRA) and 1 (PRA). Additionally, they have the option to eliminate PRA with an area smaller than a certain threshold. Therefore, the algorithm of Veitinger et al. (2016) was extended by the option to set a probability threshold for discrete classification and the option to define a minimum release area. The algorithm by Bühler et al. (2013) requires a value for the following input parameters: minimum slope angle, maximum slope angle, cell size for the moving window to calculate the roughness, maximum roughness, maximum curvature, minimum release area. To run the algorithms, we apply the swissALTI3D digital elevation model from swisstopo with a spatial resolution of $5 \mathrm{~m}$ (swisstopo, 2018).

Each of the selected existing algorithms requires certain values as input parameters. Depending on the value set for the input parameters, the model output varies considerably. In order to be able to compare the algorithms with each other, the following approach is chosen: the goal is to achieve the best possible performance of each algorithm and to compare it with the other algorithms. Therefore, the aim is to find the optimal values for each input parameter. To do so, for an algorithm the values of a parameter are changed systematically at a time (e.g., 20, 21 and 22 up to $40^{\circ}$ for the lower slope angle threshold) while keeping all other input parameters of this algorithm fixed (e.g., $60^{\circ}$ for the upper slope angle threshold). The default values are set based on previously published investigations (Schweizer et al., 2003; Bühler et al., 2013; Veitinger et al., 2016). After the iteration over this parameter (lower slope angle threshold), another input parameter (e.g., upper slope angle threshold) is changed systematically while the lower slope angle threshold is fixed again to the "default value" (e.g., $\left.30^{\circ}\right)$. With this approach we identify the optimal parameter settings for the tested algorithms based on the same reference data set described in Sect. 2.1. This identification of the optimal parameter settings (Fig. 3) enables an objective comparison of the performance of the different algorithms (Sect. 2.4), applying the quality measures described in Sect. 2.2 even though they apply different input parameters.

Some parameters such as the maximum slope angle or minimum release area are not sensitive and only slightly change with parameter variation. Other parameters such as the minimum slope angle or the minimum susceptibility are much more sensitive and change the output considerably. The minimum slope angle in Fig. 3a reaches percentage values of more than $100 \%$ (right axis) because we test minimum slope angles smaller than $28^{\circ}$.

\subsection{Validation results}

We compare the performance of the selected algorithms with their specific optimal parameter settings (Table 2). To quantify the optimization effect of the algorithms, we also list the percentage of PRA delimited by the respective algorithm to the PRA identified in the slope-only approach (Voellmy, 1955), which corresponds to all area with a slope angle between 28 and $60^{\circ}$. The slope-only approach has a very high POD but also a very high POFD, leading to relatively low PSS and HSS values because it basically delineates all area where avalanches can release. Even though the POD of the Veitinger et al. (2016) algorithm is $1.95 \%$ lower, the PSS is $6.44 \%$ higher because the POFD is $8.39 \%$ higher, which is a substantial improvement. In comparison, the Bühler et al. (2013) algorithm reaches a slightly lower POD of $95.06 \%$ but the highest POFD is $16.06 \%$. This leads to the highest overall quality scores of $79.01 \%$ PSS and $66.99 \%$ HSS.

The major problem of these three tested algorithms is the final delineation of the individual PRA, which is the base for the coupling with dynamic avalanche models. The slopeonly and Veitinger et al. (2016) algorithms do not delineate 

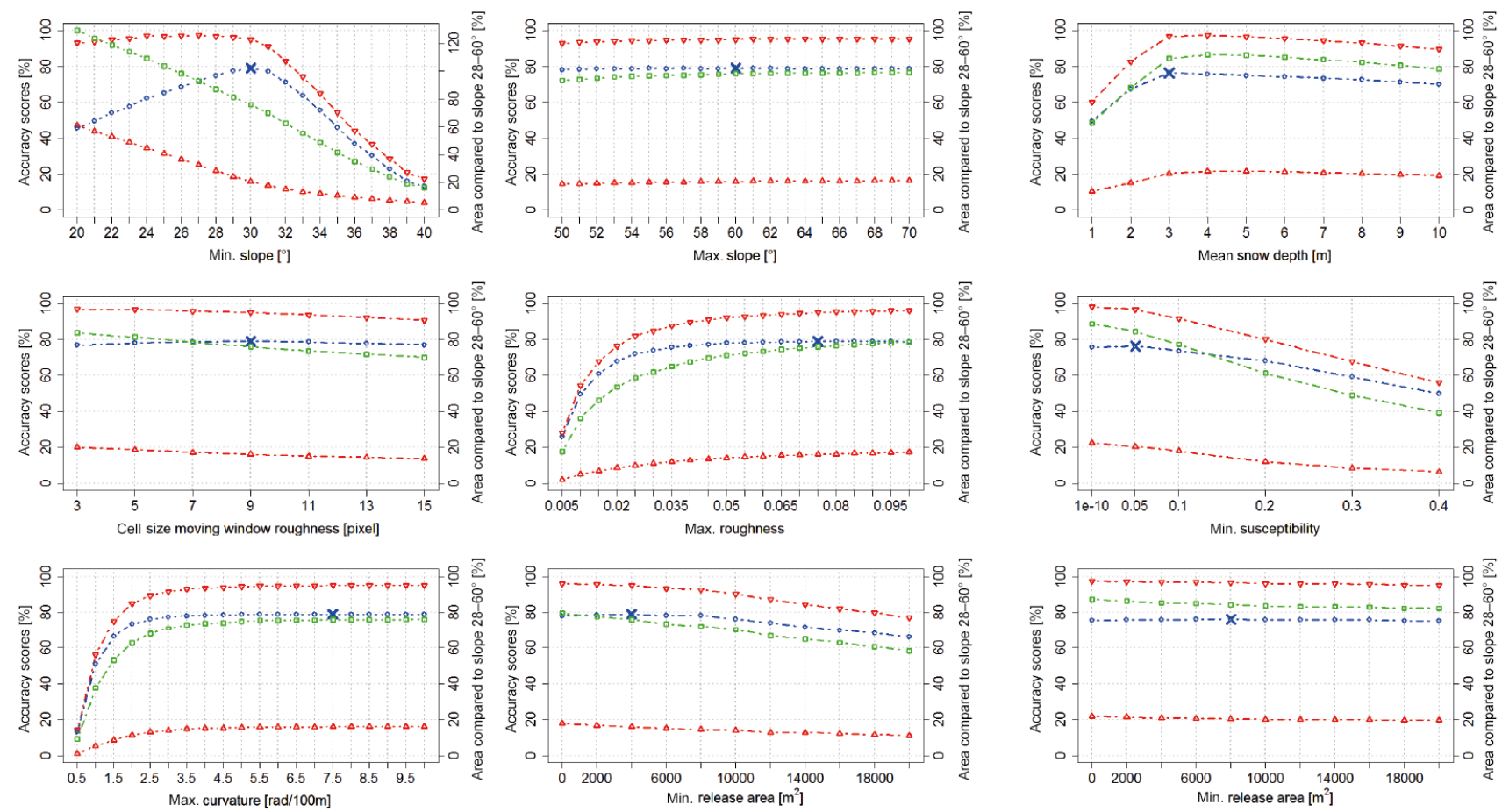

(a)

$$
\rightarrow-P O D \quad \rightarrow-\text { POFD } \quad \rightarrow-\text {-PSS } \quad \rightarrow-\text { Area [\%] }
$$

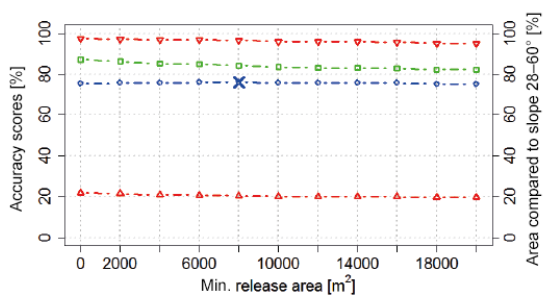

(b) $\rightarrow-$-POD $\rightarrow$-POFD $\rightarrow-$-PSS $\rightarrow-$-Area [\%]

Figure 3. Identification of the optimal input parameter settings for the selected algorithms: (a) Bühler et al. (2013) and (b) Veitinger et al. (2016). The blue crosses indicate the derived optimal parameter values. The accuracy measures POD, POFD and PSS are depicted on the left axis. The percentage of identified area compared to the benchmark after Voellmy (1955) corresponds to the right axis.

Table 2. Performance of the tested algorithms compared to the manually mapped avalanche release areas at all three test sites, Parsenn, Jakobshorn and Rinerhorn (Fig. 1).

\begin{tabular}{lrrrrr}
\hline & $\begin{array}{r}\text { POD } \\
(\%)\end{array}$ & $\begin{array}{r}\text { POFD } \\
(\%)\end{array}$ & $\begin{array}{r}\text { PSS } \\
(\%)\end{array}$ & $\begin{array}{r}\text { HSS } \\
(\%)\end{array}$ & $\begin{array}{r}\text { Area compared to } \\
\text { slope 28-60 }(\%)\end{array}$ \\
\hline Voellmy (1955), slope only & 98.69 & 28.89 & 69.80 & 51.72 & 100.00 \\
Bühler et al. (2013) & 95.06 & 16.06 & 79.01 & 66.99 & 75.91 \\
Veitinger et al. (2016) & 96.74 & 20.50 & 76.24 & 61.45 & 84.41 \\
\hline
\end{tabular}

individual PRA. The Bühler et al. (2013) algorithm applies a basic delineation based on flow direction but the results are unsatisfactory because artificial straight lines of delineation occur (Fig. 4). As dynamic avalanche models are very sensitive to PRA location and volume, only a sophisticated delineation of the PRA can be applied for meaningful scenariobased modeling.

\section{Object-based image analysis approach}

To overcome the abovementioned issues concerning PRA delineation, we develop a new algorithm based on object based image analysis (OBIA), originally developed to analyze remote-sensing data (Blaschke, 2010), applying the Trimble eCognition Developer 9.3 software. The OBIA al- gorithm is based on the Bühler et al. (2013) algorithm and optimizes the delineation process.

\subsection{Input data sets}

To run the OBIA analysis we use the swissALTI3D DEM provided by swisstopo, with a spatial resolution resampled from the original $2 \mathrm{~m}$ to $5 \mathrm{~m}$. In several tests including manual evaluation with avalanche experts, we concluded that a $5 \mathrm{~m}$ resolution is sufficient to picture the terrain features relevant for avalanche release. We apply the elevation and its derivatives: slope angle, terrain ruggedness, aspect and fold (Fig. 5). Additionally, we apply a forest layer, which is binary (forest or no forest). The most important parameters and their settings are described in the following. 

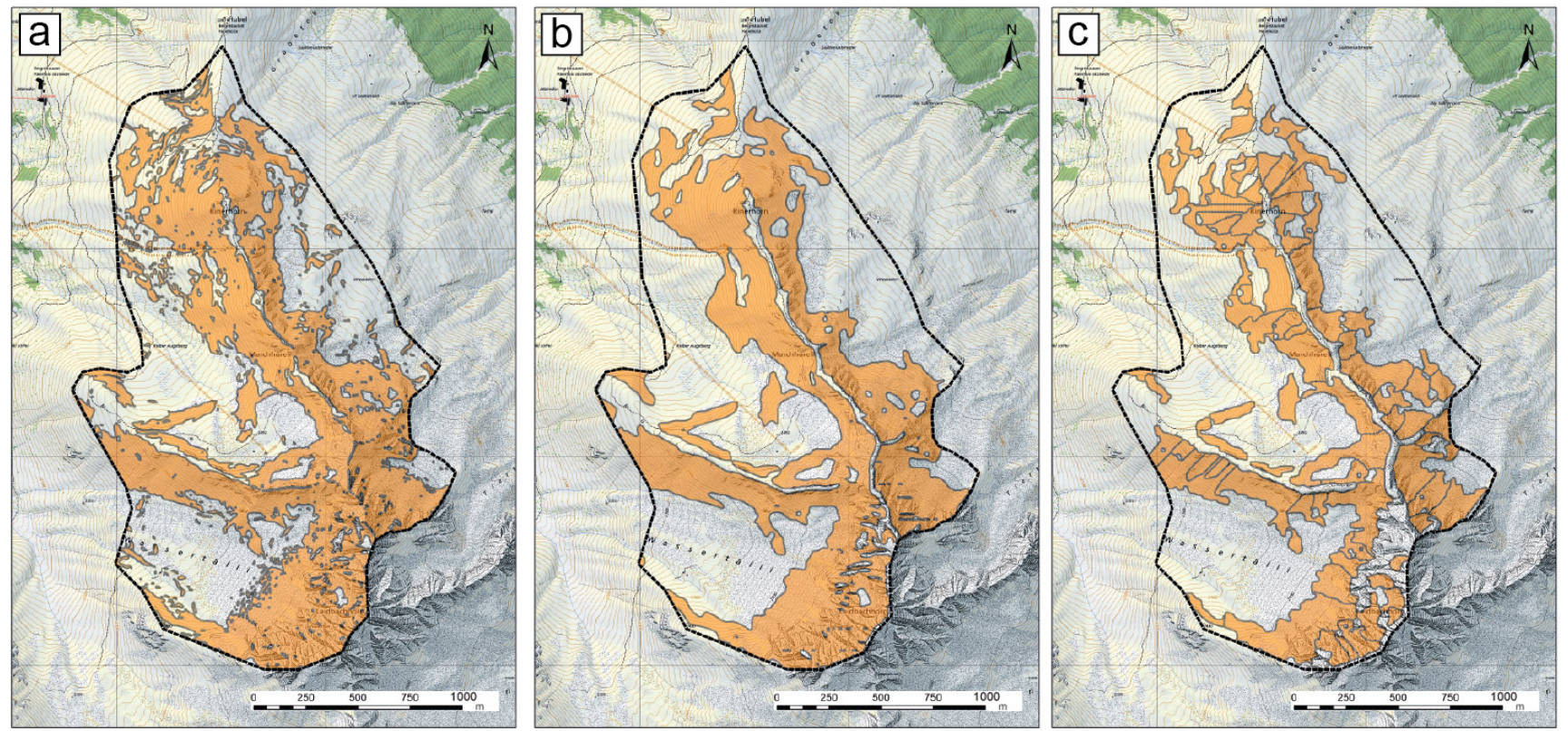

Figure 4. Results of the best parameter setting for the algorithms from (a) Voellmy (1955), (b) Veitinger et al. (2016) and (c) Bühler et al. (2013) for the test site Rinerhorn illustrating the missing or insufficient delineation of the individual PRAs (pixmaps $\odot 2018$ swisstopo (5704 000 000), reproduced with the permission of swisstopo (JA100118)).

Slope angle (Burrough and McDonnell, 1998) is the first derivation of the elevation and describes the inclination of the terrain based on the elevation difference from the highest to the lowest adjacent cell in degrees and is a key parameter for avalanche release. To avoid a very unsettled picture caused by slope changes between single pixels, we filter the slope angle by applying a $5 \times 5$ cell mean filter, weight by distance. This step eliminates isolated steep pixels as well as isolated flatter pixels. The filtered slope angle is a meaningful base to generate homogenous objects.

Aspect (Burrough and McDonnell, 1998) describes the downslope direction of the maximum rate of change from each cell to its neighbors. This describes the exposition of the terrain or the slope direction. We classify the DTM pixels into the eight aspect sectors north, northeast, east, southeast, south, southwest, west and northwest. This is a key feature to delineate between the different PRAs as a change in exposition usually limits the crack propagation (Van Herwijnen et al., 2016).

Curvature (Burrough and McDonnell, 1998) is the first derivation of the aspect or slope and parameterizes the convexity and concaveness of terrain (unit: $\operatorname{rad} 100 \mathrm{hm}^{-1}$ ). This can be performed along the fall line of the slope (profile curvature) or across the fall line (plan curvature). We apply the plan curvature to eliminate highly convex or concave areas limiting the fracture propagation of avalanche release (Van Herwijnen et al., 2016). The profile curvature is measured as the change in slope angle, and the plan curvature as change in aspect.
Ruggedness (Sappington et al., 2007) is a slope angle independent measure for terrain roughness. Very rough terrain such as ridges and gullies prevents a widespread, connected weak layer and therefore the release of avalanches (Schweizer et al., 2003). To calculate the ruggedness, a window size has to be specified. We apply a window size of 9 pixels, which corresponds to $45 \mathrm{~m}$ at an input resolution of $5 \mathrm{~m}$. Within this window all normal vectors to the ground are analyzed and their deviation is calculated. The result is a layer with normalized values between 0 (completely flat) and 1 (normal vectors diverge by $360^{\circ}$ ). Rough terrain starts at values around 0.03 and after 0.08 the terrain is very rough. Values larger than 0.1 occur only very sparsely in natural terrain.

Fold describes the change of adjacent normal vectors of the topography defined by the grid cells and therefore is a good indicator for ridges and gullies as well as other abrupt terrain changes (Schmudlach and Köhler, 2016). As with ruggedness, fold has no unit. This is also key information to delineate between different PRAs.

\subsection{Processing steps}

To produce the PRA for the frequent scenario, we first identify steep slopes between 30 and $60^{\circ}$. Then we subtract areas with high roughness $(>0.06)$ and high plan curvature values $\left(>6 \mathrm{rad} 100 \mathrm{hm}^{-1}\right)$ to eliminate gullies, ridges and rough rock faces, where no consecutive weak layer can develop and no large snow masses can deposit (Schweizer et al., 2003; Wirz et al., 2011). Additionally, isolated PRAs smaller than 

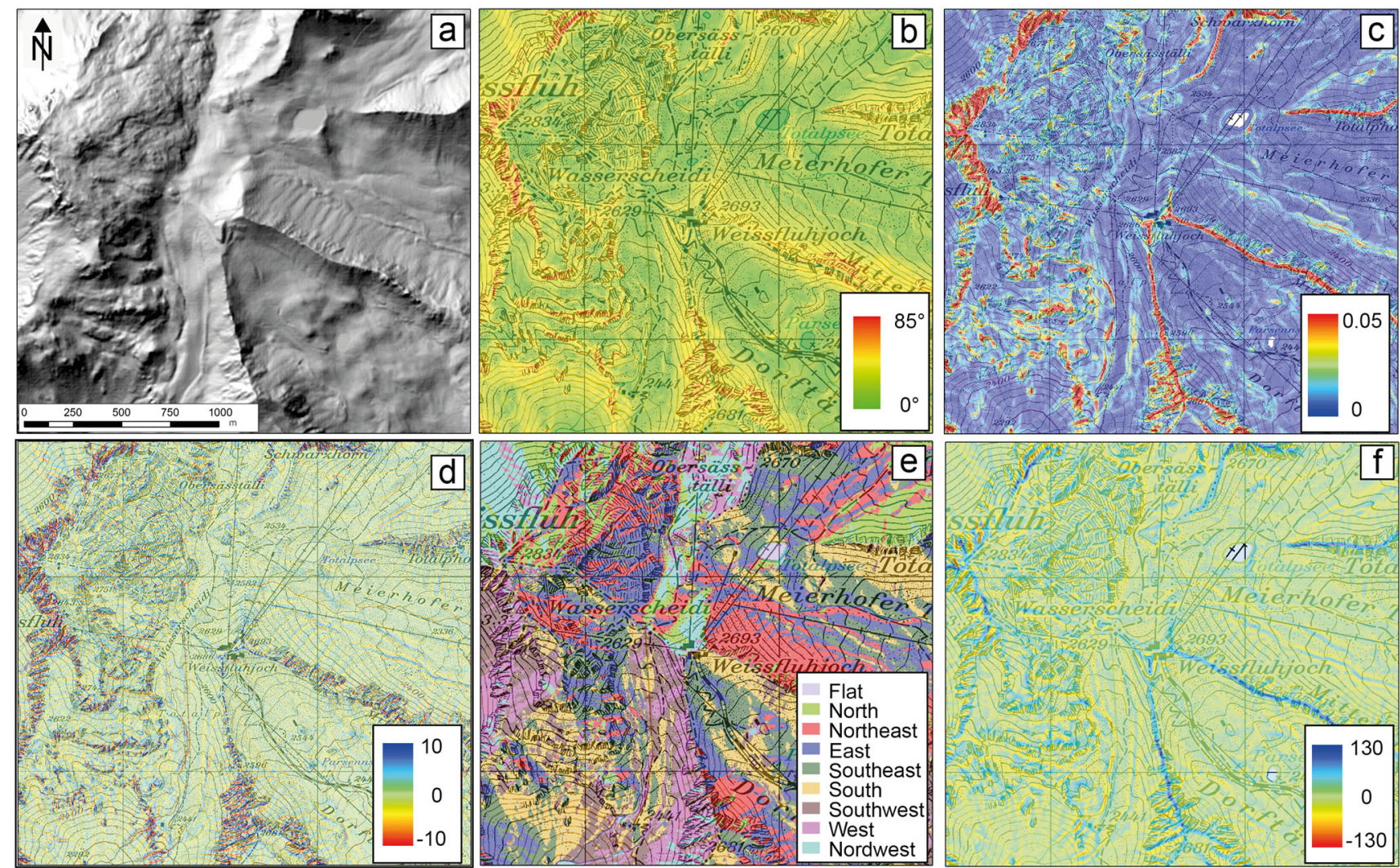

Figure 5. Input data to delineate the PRA derived from the digital elevation model, at the Weissfluhjoch region in the ski resort Parsenn as an example: (a) hillshade of the DTM, (b) slope angles, (c) ruggedness, (d) plan curvature, (e) aspect and (f) fold. The location of this subset is depicted in Fig. 8 (blue box) (pixmaps@ 2018 swisstopo (5704 000 000), reproduced with the permission of swisstopo (JA100118)).

$500 \mathrm{~m}^{2}$ are excluded. This first layer is then segmented and classified into objects that are susceptible for PRA and NoPRA objects (Fig. 6a).

In a second step, the susceptible area is further segmented with a finer-scale parameter. We apply a multiresolution segmentation that considers variations in aspect sectors, slope and fold. We weigh variations in aspect sectors 3 times more than variations in slope and fold as changes in aspect sector are the most important delineation parameters between individual PRAs (Fig. 6b). Finally, we classify PRAs that are covered by forest (Fig. 6c).

To produce the PRA for the extreme scenario, we change the slope angle $\left(28-60^{\circ}\right)$ and the ruggedness threshold ( $>0.08$ ) to enable larger and more connected PRA (Fig. 7a). Then we apply the same process tree as for the PRA in the frequent scenario. The small PRAs are then classified after their median into the aspect sector classes (Fig. 7b). Then we apply a region growing algorithm to merge adjacent objects with similar exposition, based on fold and slope angle. Finally, we classify PRAs that are covered by forest (Fig. 7c).

\subsection{Results}

To visualize the results of the OBIA-based PRA algorithm, we look at the greater region of Davos, with an extent of 20 by $25 \mathrm{~km}$, which equals $500 \mathrm{~km}^{2}$. This area includes the three test sites Parsenn, Jakobshorn and Rinerhorn, depicted with dashed lines in Fig. 8. Figure 9 gives a close up of the test site Rinerhorn. For the frequent scenario we obtain 16167 individual release polygons. The mean area is $9750 \mathrm{~m}^{2}$ and the mean slope angle is $35.85^{\circ}$. For the extreme scenario we calculate 8332 PRAs with a mean area of $22850 \mathrm{~m}^{2}$ and a mean slope angle of $33.80^{\circ}$. Applying this approach, PRAs for the frequent and extreme scenarios are directly connected. The extreme PRAs consist of connected frequent PRAs with similar exposition, fold and slope. However, the total area is not exactly the same as we change the input layer thresholds for slope from 30 to $28^{\circ}$ and the ruggedness threshold from 0.06 to 0.08 from the frequent scenario to the extreme scenario. This leads to larger and more connected PRA for the extreme scenario, which is in good agreement with the qualitative visual assessment performed by experienced SLF experts.

The validation described in Sect. 2.2 is now also applied to the OBIA algorithm (Table 3). The OBIA algorithm for the 

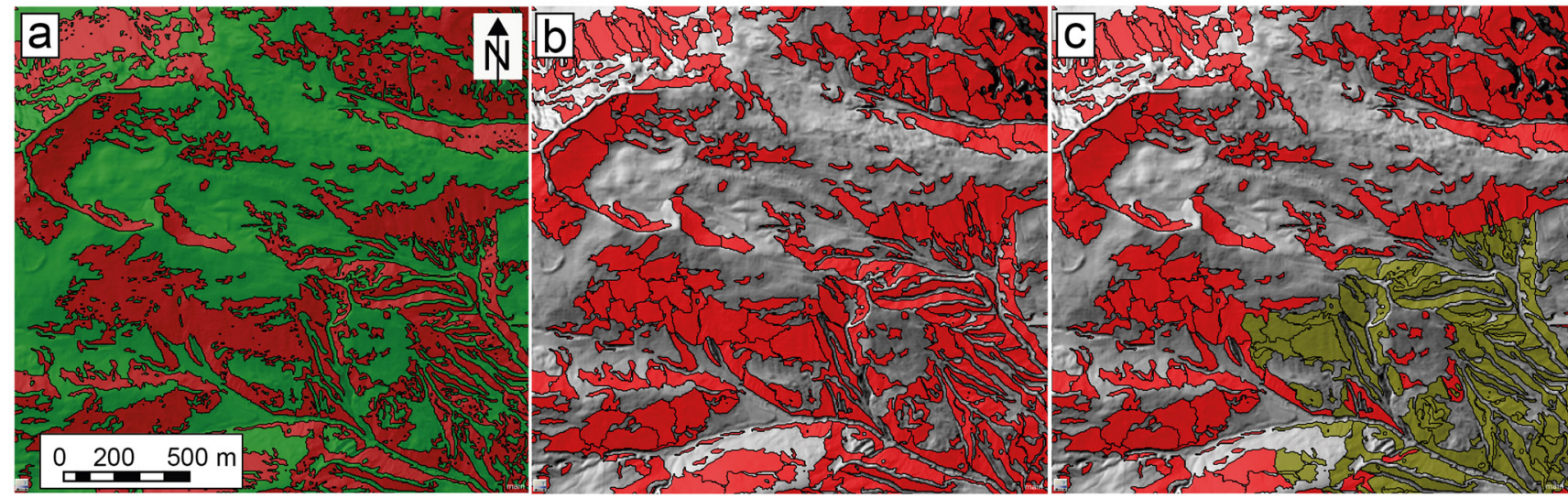

Figure 6. Segmentation and classification of the terrain based on slope angle and ruggedness into PRA (red) and non-PRA (light green) (a). Then the PRAs are further segmented based on elevation, aspect, slope and fold (b). Finally, the PRAs are classified as forest covered (dark green) and not forest covered (red) (c) resulting in the PRA for the frequent scenario. The location of this subset is depicted in Fig. 8 (green box).
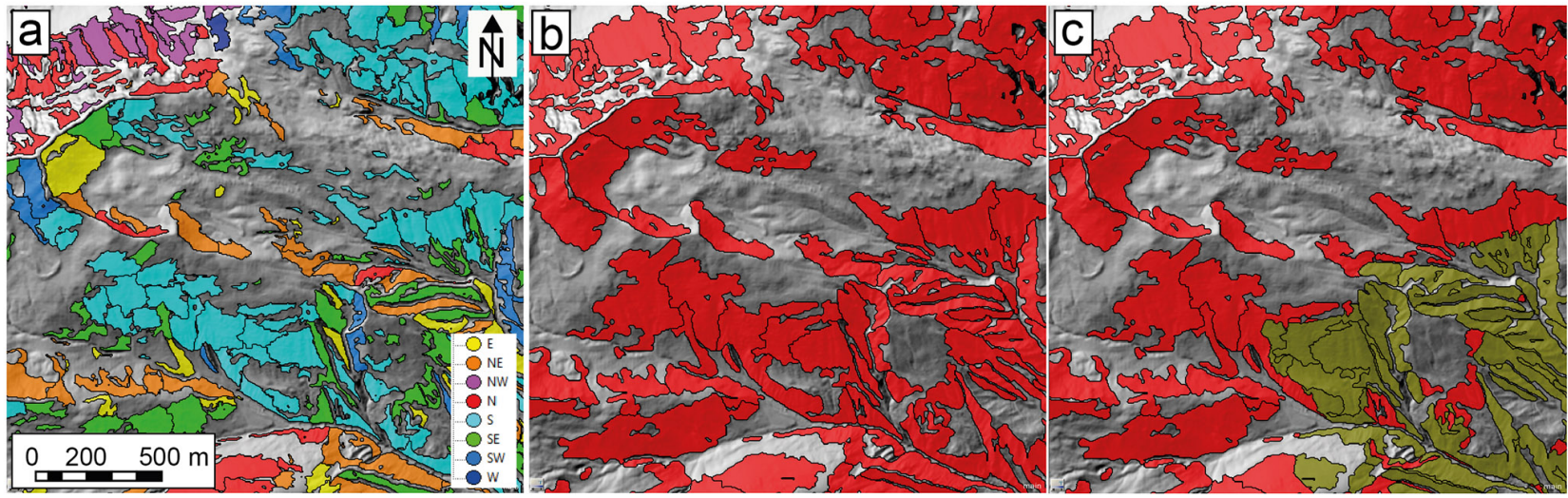

Figure 7. Classification of the frequent PRAs based on their most frequent aspect sectors (a). Regions grow into object with similar exposition based on fold and slope angle (b). Classification of the forest-covered objects in green (c) resulting in the PRA for the extreme scenario. The location of this subset is depicted in Fig. 8 (green box).

frequent scenario is slightly better in POD and POFD than the Bühler et al. (2013) algorithm and exhibits an improved delineation of the individual PRAs. The comparison of the algorithms of Veitinger et al. (2016) and Voellmy (1955) to the OBIA algorithm reveals a better performance, which is quantified by the higher PSS and HSS scores and the lower amount of total delineated area.

\subsection{Calculation of avalanche release depth $(d 0)$ and avalanche release volume}

To perform an avalanche dynamics simulation not only the release area and its location are needed but also an average release depth, measured perpendicular to the slope. Combining these two pieces of information, the avalanche volume can be calculated. In state-of-the-art avalanche dynamic models such as RAMMS, the applied friction values depend on the release volume (Christen et al., 2010).

We implement the release depth calculation approach developed by Salm et al. (1990), which is applied for hazard mapping in Switzerland and is therefore well established. The estimation of release depth is based on the maximum snow depth increase within 3 days $\Delta \mathrm{HS}(3)$, measured at automatic weather stations or study plots. These values are extrapolated using the Gumbel extreme value statistics (Bocchiola et al., 2008). The longer the time series of snow depth measurements are and the more extreme the weather events that are captured, the more reliable the extrapolation becomes. In Switzerland the maximum extrapolation time period applied is 300 years as it makes not much sense to further extrapolate by applying measurement series not reaching back more than 85 years. However, in other countries, for ex- 

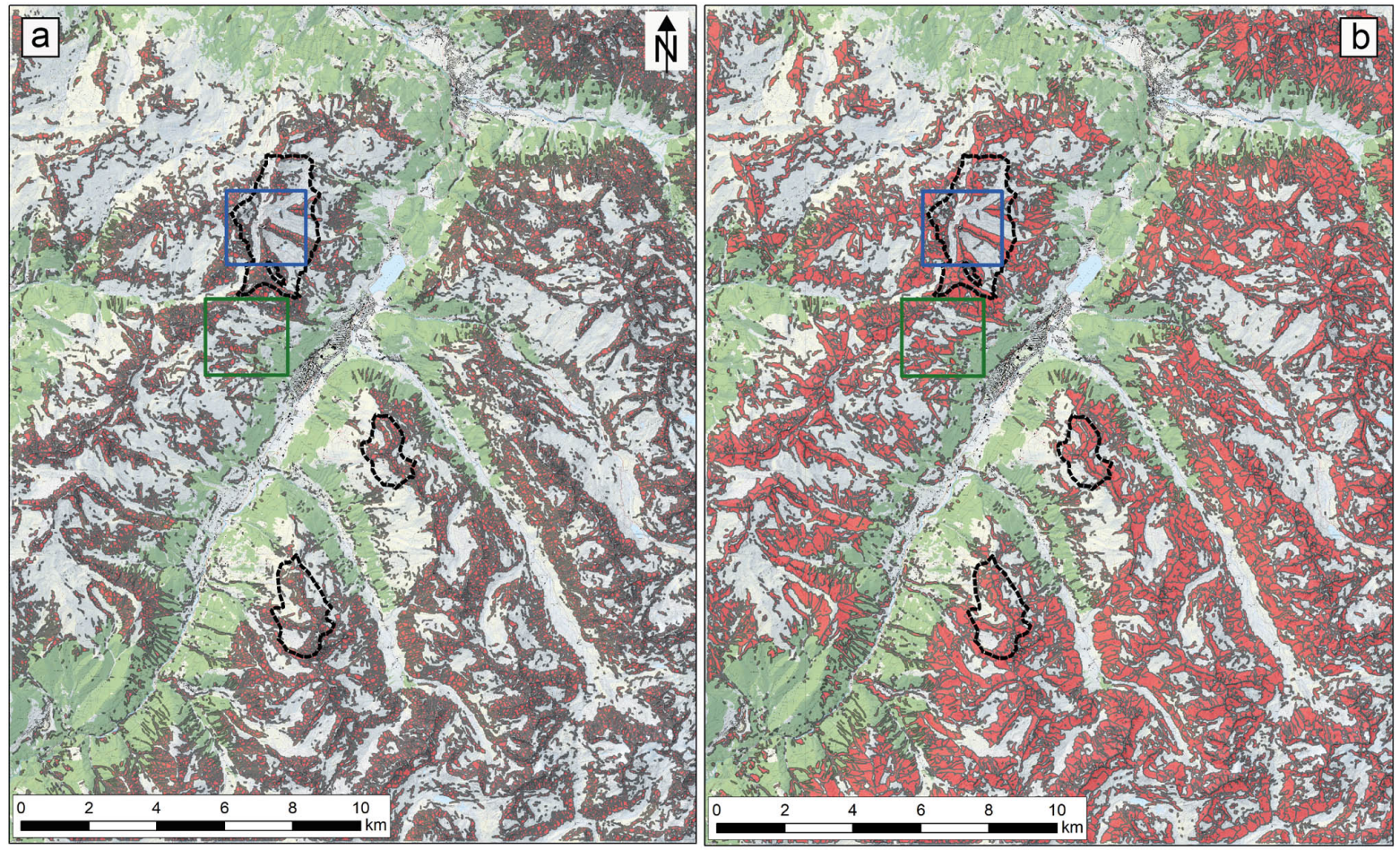

Figure 8. Results for the OBIA-based PRA algorithms for the frequent scenario (a) and the extreme scenario (b) without the PRA in forests. In dashed lines the extents of the test regions Parsenn (north), Jakobshorn (center) and Rinerhorn (south) are depicted. The extent of Fig. 5 is depicted as a blue box and the extent of Figs. 6 and 7 is depicted as a green box (pixmaps@ 2018 swisstopo (5704 000 000), reproduced with the permission of swisstopo (JA100118)). Data are from Bühler and von Rickenbach (2018).

Table 3. Validation results of all tested algorithms.

\begin{tabular}{lrrrrr}
\hline & $\begin{array}{r}\text { POD } \\
(\%)\end{array}$ & $\begin{array}{r}\text { POFD } \\
(\%)\end{array}$ & $\begin{array}{r}\text { PSS } \\
(\%)\end{array}$ & $\begin{array}{r}\text { HSS } \\
(\%)\end{array}$ & $\begin{array}{r}\text { Area compared to } \\
\text { slope 28-60 }(\%)\end{array}$ \\
\hline Vollmey (1955), slope only & 98.69 & 28.89 & 69.80 & 51.72 & 100.00 \\
Bühler et al. (2013) & 95.06 & 16.06 & 79.01 & 66.99 & 75.91 \\
Veitinger et al. (2016) & 96.74 & 20.50 & 76.24 & 61.45 & 84.41 \\
OBIA frequent & 95.22 & 15.57 & 79.65 & 67.85 & 75.07 \\
OBIA extreme & 97.84 & 19.78 & 78.06 & 63.21 & 83.72 \\
\hline
\end{tabular}

ample in Norway, this approach is applied to extrapolate as far as for 5000 years (Rudolf-Miklau et al., 2014). For the station Davos Flüelastrasse (1560 m a.s.1.), which we apply for this study, the $\Delta \mathrm{HS}(3)$ for the frequent scenario (10-year return period) is $0.82 \mathrm{~m}$. For the extreme scenario (300-year return period) it is $1.44 \mathrm{~m}$.

Now an elevation correction factor is applied to account for increasing snow depth with increasing elevation. In Switzerland $\pm 5 \mathrm{~cm}$ is applied per $100 \mathrm{~m}$ of elevation difference. The work of Blanchet et al. (2009) found a value close to $\pm 2 \mathrm{~cm}$ per $100 \mathrm{~m}$ elevation difference, which might be more realistic for most regions in the Alps. To transform the $\Delta \mathrm{HS}(3)$ measured at the flat field into the inclined slope of the release area, the values are corrected by mul- tiplying it with the cosine of $28^{\circ}$ in a first step. If necessary the snow depth value is increased by a factor for wind load. In practice, values from 10 to $50 \mathrm{~cm}$ are used depending on the expected additional wind load. Finally, the correction for the inclination of the release area is applied for the final calculation of the fracture depth $d 0$, using the function $\Psi=0.219 / \sin (\alpha)-0.202 \times \cos (\alpha)$ of the slope angle $\alpha$. The basic idea behind this approach is the observation that steep slopes accumulate less snow than flatter slopes as the snow on steep slopes is less stable. These calculation steps are implemented in a Python script that calculates an individual release depth for every PRA polygon based on the mean elevation and the mean slope angle of the polygon. Based on the $d 0$ value the release volume for every PRA is calculated 

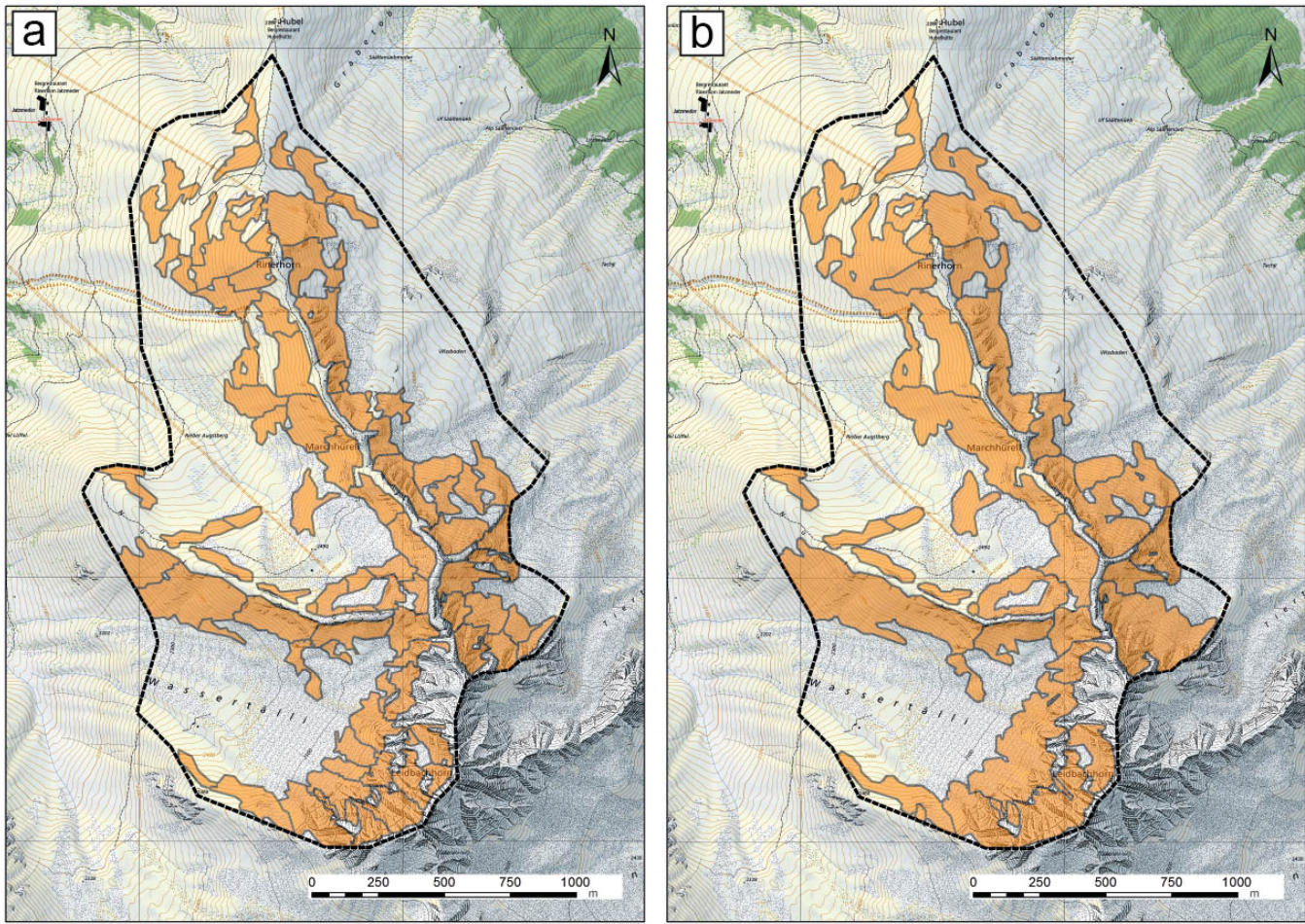

Figure 9. Results of the OBIA algorithm for the frequent scenario (a) and the extreme scenario (b) at the test site Rinerhorn (pixmaps@ 2018 swisstopo (5704 000000$)$, reproduced with the permission of swisstopo (JA100118)).

for both scenarios. The mean $d 0$ for the frequent scenario in the region of Davos is 0.85 and $1.60 \mathrm{~m}$ for the extreme scenario. The mean release volumes are $10350 \mathrm{~m}^{3}$ (frequent) and $41600 \mathrm{~m}^{3}$ (extreme).

\subsection{Numerical avalanche dynamic simulations}

The calculated release areas and the release depth define the avalanche release volume, which is necessary as input for the numerical avalanche dynamic simulations. We adapted the RAMMS::AVALANCHE software (Christen et al., 2010), applied for the generation of hazard maps, to automatically process a large number of release areas. This new module, RAMMS::LSHM, applies the well-established friction parameter sets defined by Gruber and Margreth (2001) to all PRA polygons generated with the OBIA algorithm described in Sect. 3. We split the PRA polygons into four volume classes as defined in Christen et al. (2010) and apply their specific friction parameters given in Table 4

The resulting maximum avalanche pressure values shown in (Fig. 10) are later classified to a large-scale hazard indication map.

\section{Discussion}

\subsection{Validation of existing algorithms}

The validation of PRA is a very difficult task as avalanche release areas often occur in poorly accessible terrain and may not be observed in time due to new snowfall or snow drift. Furthermore, accurate mapping of observed release areas is very demanding in complex and steep terrain. In the region of Davos there are a lot of avalanche mapping activities performed by SLF and the local ski patrol staff but in most cases only the avalanche outline is mapped manually and not the release area specifically. The uncertainty concerning avalanches that have occurred but were not mapped is very high. Accurate avalanche mapping based on optical or radar aerial imagery or satellite data with sufficient spatial resolution can only be applied occasionally due to high data acquisition costs (Bühler et al., 2009; Lato et al., 2012; Eckerstorfer et al., 2016; Korzeniowska et al., 2017). Therefore, no complete reference data sets over longer time periods exist to our knowledge. To overcome this limitation and to enable a meaningful quantitative validation of the algorithms, we produce a manually completed reference data set for three test sites (Sect. 2.1). Since the automatic PRA delineation was carried out with regard to hazard indication mapping, high values for POD are requested to not miss PRAs that could 
Table 4. RAMMS friction parameters applied for the simulation of the PRA for the frequent and extreme scenarios.

\begin{tabular}{lrr|rr}
\hline & \multicolumn{2}{c|}{ Frequent scenario } & \multicolumn{2}{c}{ Extreme scenario } \\
\cline { 2 - 5 } Volume categories & $\mu$ & $\begin{array}{r}\xi \\
\text { (turbulent friction) }\end{array}$ & $\begin{array}{r}\mu \\
\text { (coulomb friction) }\end{array}$ & $\begin{array}{r}\xi \\
\text { (turbulent friction) }\end{array}$ \\
\hline Tiny $\left(<5000 \mathrm{~m}^{3}\right)$ & 0.29 & 1500 & 0.275 & 1500 \\
Small $\left(5000-25000 \mathrm{~m}^{3}\right)$ & 0.26 & 2000 & 0.235 & 2000 \\
Medium $\left(25000-60000 \mathrm{~m}^{3}\right)$ & 0.225 & 2500 & 0.195 & 2500 \\
Large $\left(>60000 \mathrm{~m}^{3}\right)$ & 0.18 & 3000 & 0.155 & 3000 \\
\hline
\end{tabular}

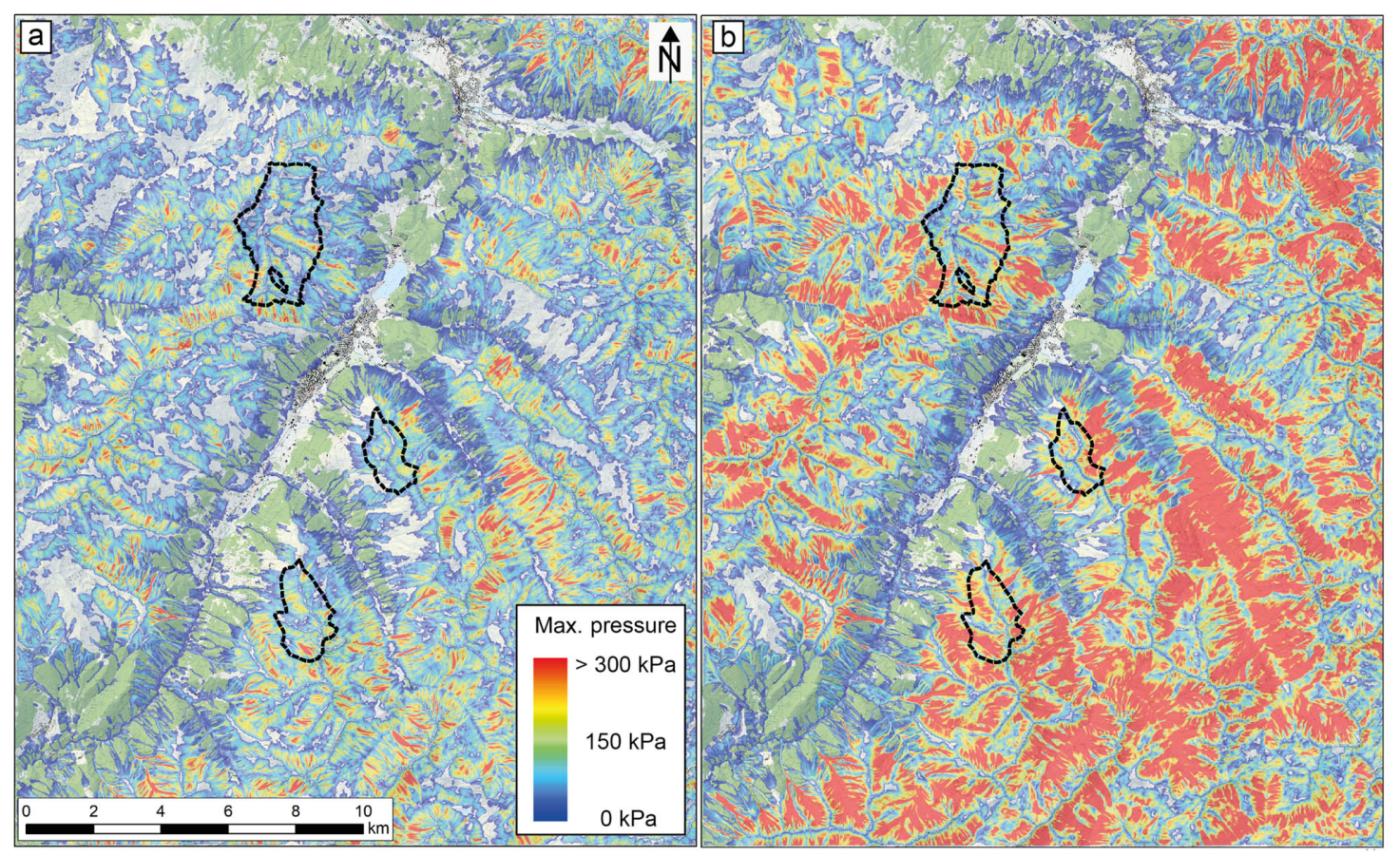

Figure 10. RAMMS-simulated maximum impact pressure values based on the PRA depicted in Fig. 8 for the frequent scenario (a) and the extreme scenario (b). In dashed lines the extents of the test regions Parsenn, Jakobshorn and Rinerhorn are depicted (pixmaps@ 2018 swisstopo (5704 000 000), reproduced with the permission of swisstopo (JA100118)). Data are from Bühler and von Rickenbach (2018).

produce destructive avalanches. For other purposes such as scenarios with very short return periods ( $1-5$ years) usually applied for traffic line safety assessment, a lower POFD is maybe more important. To enable a validation that is as objective as possible, we calculated the best parameter setting for every investigated algorithm based on the reference data set (Sect. 2.2).

The validation shows that the POD is best with a value of $98.69 \%$ for the simple slope angle approach even though not $100 \%$ are reached because of mapping errors in the reference data set and isolated PRA section above $60^{\circ}$. However, the POFD is $28.89 \%$, limiting its applicability for largescale hazard indication mapping because numerous unrealistic avalanches would be simulated. This leads to low overall accuracy measures $(\mathrm{PSS}=69.80 \%, \mathrm{HSS}=51.72 \%$ ).
The algorithm based on Veitinger et al. (2016) reduces the POFD to $20.50 \%$ due to consideration of terrain roughness (dependent on snow depth) but keeps a high POD of $96.74 \%$. These values indicate the suitability of this algorithm for large-scale hazard indication mapping, resulting in higher overall accuracy measures (PSS $=76.24 \%$, HSS $=61.45 \%$ ). This algorithm was developed to analyze avalanche release probabilities for smaller areas such as avalanche-prone slopes next to single road sections in combination with snowpack and meteorological data for near-realtime hazard assessment and not for large-scale hazard indication mapping. With the focus on single slopes, this algorithm does not delineate individual PRAs, which would be mandatory for the numerical avalanche simulations.

The algorithm based on Bühler et al. (2013) achieves a slightly lower POD of $95.06 \%$ but an improved POFD of 
$16.06 \%$. In addition to the roughness, this algorithm also excludes areas with high curvature values. This leads to the highest overall accuracy measures of the three tested algorithms $(\mathrm{PSS}=79.01 \%, \mathrm{HSS}=66.99 \%)$. Additionally, this algorithm tries to separate into individual PRAs based on flow direction. But no scenarios can be depicted with this approach and the delineation of the individual PRA is unsatisfying.

The largest performance differences among the tested algorithms are not in the POD, which is very good for all algorithms, but in the POFD for which we find considerable differences. Low POFD values mean that much less area is delineated as PRA, saving many time-consuming numerical simulations. For example, the Bühler et al. (2013) approach results in $24 \%$ less PRA than the slope-only approach.

\subsection{Development and performance of the new object-based image analysis (OBIA) approach}

To overcome the limited possibilities, present in the tested algorithms for the delineation of the final PRA polygons, we develop a new PRA algorithm (Sect. 3). With this algorithm, different scenarios with varying PRA sizes can be generated, which is a big advantage for large-scale hazard indication mapping. The OBIA algorithm for the frequent scenario (530 -year return period) achieves a POD of $95.39 \%$ and the lowest POFD value of $15.88 \%$, eliminating most areas where avalanches do not occur. Therefore, this algorithm achieves the highest overall accuracy measures of all tested algorithms (PSS $=79.51 \%, \mathrm{HSS}=67.47 \%$ ). This result proves the high performance of the newly developed OBIA algorithm for the frequent scenario.

Additionally, the OBIA algorithm was extended for an extreme avalanche scenario (100-300-year return period). The individual PRAs grow into areas with minimum slope inclination of $28^{\circ}$ and rougher terrain. They are generated in the same way as for the frequent scenario but are then merged based on aspect, curvature and slope to obtain larger PRAs. This increases the POD to $97.84 \%$ but also increases the POFD to $19.78 \%$; the overall accuracy measures are reduced to PSS $=78.06 \%$ and $\mathrm{HSS}=63.21 \%$. Because the validation data sets contain mainly small to medium PRAs and only very few PRAs of large avalanches, the validity of the reduced overall accuracy measures is limited. Unfortunately, no complete data sets for large PRAs exist to our knowledge to meaningfully validate an extreme PRA scenario. Maybe this will change in the future as more cadaster information over longer periods becomes available and satellite imagery can be applied to accurately map extreme avalanche cycles.

The OBIA algorithm is a novel and useful approach to generate two different PRA scenarios for large-scale hazard indication mapping and enables regional- to national-scale applications. In particular in regions where no or only limited avalanche cadasters exist and no experienced avalanche engineers have produced hazard maps, such an automated approach can be very helpful for a preliminary hazard assessment. The delineation of the individual PRA is very difficult to validate. Compared to the algorithm of Bühler et al. (2013), only the OBIA algorithm performs a specific delineation of the individual PRA and shows obvious improvements in particular within homogenous slopes (Figs. 4 and 9). This is achieved by the improved implementation of the aspect, curvature, fold and slope terrain characteristics into region growth algorithms within the eCognition software. However, further investigations are needed to validate, refine and extend the delineation of the individual PRA, the definitions of the different scenarios and the adaption to specific local conditions.

\subsection{Automated hazard indication mapping}

Already in 2004 the project SilvaProtect performed automated avalanche dynamic simulations over the entire area of Switzerland to identify protection forests (Gruber and Baltensweiler, 2004). At this time the digital elevation model available only had a resolution of $25 \mathrm{~m}$ (DHM25) and only a single scenario was calculated with a precursor version of RAMMS (AVAL-2D). The delineation of two PRA scenarios generated with the OBIA approach enables, for the first time, the calculation of dynamic numerical avalanche simulations over large areas with detailed terrain resolution. In combination with extrapolated extreme snow depth values describing potential release volumes, meaningful hazard intensity maps are generated that can be easily translated into hazard indication maps. The procedure follows the simulation part that is applied for operational hazard mapping in Switzerland but can now also be applied to areas of up to several thousands of square kilometers in regions where no hazard maps exist. A preliminary validation of the results with existing hazard maps in the canton Grisons, Switzerland (http://map.geo.gr.ch, last access: 4 December 2018), and evaluation by local avalanche experts show a high quality of the automatically generated product (Fig. 11). This approach opens the door for spatially continuous hazard indication information, which is today available in Switzerland only with a very generalized level of detail. The direct comparison between the results of SilvaProtect (Gruber and Baltensweiler, 2004) and the approach presented in this investigation demonstrate that the results of the new approach are much more complete and accurate, mainly due to the better DEM data and the refined PRA algorithm.

The comparison of the automated hazard indication maps to the hazard maps and the database information generally show a very good agreement (Fig. 11). However, for some avalanche tracks such as the one in the middle of the map coming from the south, no hazard maps exist. This can be due to existing mitigation measures such as avalanche dams or snow supporting structures, which are not taken into account for the automated simulations or due to missing observations and therefore no detailed hazard assessment was 

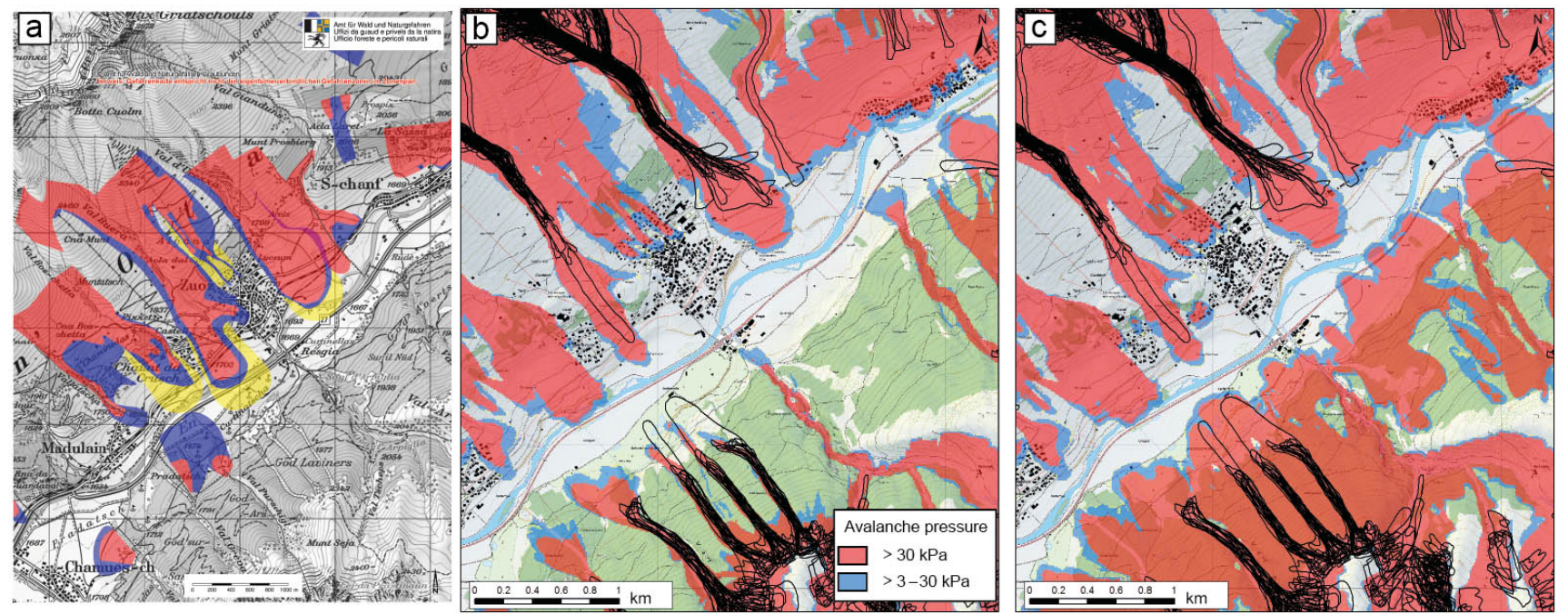

Figure 11. Comparison of the official hazard map (a) with the results of the automated hazard indication mapping procedure with forest taken into account (b) and without forest taken into account (c) and the overlaid avalanche database (black outlines) in the region of Zuoz, GR, Switzerland (pixmaps@ 2018 swisstopo (5704 000 000), reproduced with the permission of swisstopo (JA100118)).

performed. But the major differences between the automated approach and the hazard maps can be explained by the applied forest layer. The protection forest is highly dynamic and the forest in high elevations in Switzerland shows a tendency to grow more dense (Bebi et al., 2009). Since the avalanche database contains events recorded more than 60 years ago, changes in forest occurred at several locations. Most obvious is this for the two avalanche runouts from the database reaching the valley floor in the southwestern part of the map: the database's runout distances are poorly simulated in the scenario with forest but well modeled in the scenario without forest. These events were observed in 1986 when the forest structure was less dense and contained more larch trees than today. This example illustrates the crucial role of forest information for large-scale hazard indication mapping in regions with protection forests. In the future, with better up-to-date forest information derived from remote sensing (Waser et al., 2015), this source of error might be less important.

In this research we present the processing chain for dry snow flowing avalanches. By incorporating information on snow temperature, snow erosion and free water content, this approach could be extended with the scientific version of RAMMS (Bartelt et al., 2016; Bartelt and Buser, 2016) to simulate powder snow avalanches, wet snow avalanches, small-skier-triggered avalanches or glide snow avalanches. However, the validation of such simulations is very demanding in terms of valuable reference data but is planned for the future.

\section{Conclusions and outlook}

The development of automated potential release area (PRA) delineation algorithms based on digital elevation models (DEMs) started in the early 2000s. As high-quality DEM data becomes more and more available even for mountain areas in remote regions (Bühler et al., 2012), such approaches now have the potential to be combined with numerical avalanche simulations to produce automated hazard indication maps. The validation of three different published approaches based on a nearly complete avalanche reference data set from the region of Davos, Switzerland, reveals that the current detection performance of these algorithms is quite good (PSS $69.80 \%-79.01 \%)$. The algorithms considering more than just slope angle improve the accuracy of the PRA delineation. Considering just slope angle works well for smooth terrain. For rough terrain, however, curvature and roughness provide essential additional information, which should be considered in a successful algorithm. Important for the coupled numerical simulations is the total area delineated as PRA as every simulation consumes computational power and time. The tested algorithms reduce the total PRA by up to $24.09 \%$, resulting in much fewer individual simulations and producing a more realistic output. However, the delineation of the individual PRA is insufficient and no connection to hazard scenarios is possible.

Therefore, we develop and validate a new PRA delineation algorithm, based on object-based image analysis (OBIA), which performs even better (PSS 79.51\%), limits the total PRA area by $24.30 \%$ and produces PRA with meaningful delineation. A meaningful validation of the PRA delineation would be of great value. However, such reference data do not 
to our knowledge yet exist. With the OBIA approach it is possible to produce different hazard scenarios linked to return periods as the individual size of the PRA is variable. This is the prerequisite to produce meaningful hazard indication maps to automatically evaluate avalanche hazard over large areas. The comparison to existing hazard maps shows a good agreement and illustrates the potential value of such maps in particular for regions where not much information and experience with avalanche hazard exist. In any case, up-to-date and accurate DEM data and information on the protection forest are crucial.

Our reference data set is the most complete we know of considering PRA; however, it is only from a very limited region around Davos and does mostly contain a small PRA. Therefore, we do not know how representative this data set is for other regions. However, even though snow conditions may vary a lot among different locations, the basic terrain parameters leading to an avalanche release are estimated to be quite constant all over the world. Because we do not take information on the snow cover into account, we assume that our findings can be applied globally. But more research is necessary to prove this assumption. Most important would be a validation for the extreme scenario with a data set consisting of PRA from large avalanches. Unfortunately, such a data set is not available today with sufficient quality.

In the long term, the current work could enable the coupling of terrain information, meteorological data, snowpack simulations and numerical avalanche simulations to achieve near-real-time hazard assessment over large areas as proposed by Vera Valero et al. (2016) and Veitinger and Sovilla (2016). However, the required input information in sufficient quality and resolution necessary for such a coupled system is very hard to get. In addition, the sensitivity of the individual information components has to be evaluated carefully. To obtain a reliable hazard assessment is therefore very difficult and we do not expect results that are applicable in practice in the near future. However, to achieve this goal in the long term, we encourage all research concerning this topic.

Data availability. The produced potential release areas (PRAs) and the RAMMS simulations described in this paper are publicly available on ENVIDAT (https://doi.org/10.16904/envidat.55, Bühler and von Rickenbach, 2018).

Author contributions. YB and DvR designed the study and performed the calculations. MC and AS programmed parts of the necessary algorithms. SM and LS reviewed the results and proposed improvements. All authors contributed to the writing and validation of the paper.
Competing interests. The authors declare that they have no conflict of interest.

Acknowledgements. The authors thank Roderick Kühne and Christian Willhelm from the Amt für Wald und Naturgefahren, Kanton Graubünden, for their technical and financial support. We thank the ski patrol heads of the Davos Klosters Mountains resorts for their support to improve the PRA reference data sets: Romano Pajarola (Parsenn), Vali Meier (Jakobshorn) and Nigg Conrad (Rinerhorn). We thank Betty Sovilla from SLF for the discussions on the parameter settings for the Veitinger et al. (2016) algorithm

Edited by: Andreas Günther

Reviewed by: two anonymous referees

\section{References}

Allouche, O., Tsoar, A., and Kadmon, R.: Assessing the accuracy of species distribution models: Prevalence, kappa and the true skill statistic (TSS), J. Appl. Ecol., 43, 1223-1232, https://doi.org/10.1111/j.1365-2664.2006.01214.x, 2006.

Andres, A. J. and Chueca Cia, J.: Mapping of avalanche start zones susceptibility: Arazas basin, Ordesa and Monte Perdido National Park (Spanish Pyrenees), J. Maps, 8, 14-21, https://doi.org/10.1080/17445647.2012.668414, 2012

ASPRS: Digital elevation model technologies and applications : the DEM users manual, 1 ed., edited by: Maune, D., American Society for Photogrammetry and Remote Sensing, 2001.

Barbolini, M., Pagliardi, M., Ferro, F., and Corradeghini, P.: Avalanche hazard mapping over large undocumented areas, Nat. Hazards, 56, 451-464, https://doi.org/10.1007/s11069-0099434-8, 2011.

Bartelt, P. and Buser, O.: The relation between dilatancy, effective stress and dispersive pressure in granular avalanches, Acta Geotech., 11, 549-557, https://doi.org/10.1007/s11440016-0463-7, 2016.

Bartelt, P., Buser, O., Valero, C. V., and Bühler, Y.: Configurational energy and the formation of mixed flowing/powder snow and ice avalanches, Ann. Glaciol., 57, 179-188, https://doi.org/10.3189/2016AoG71A464, 2016.

Bebi, P., Kulakowski, D., and Rixen, C.: Snow avalanche disturbances in forest ecosystems - State of research and implications for management, Forest Ecol. Manag., 257, 1883-1892, https://doi.org/10.1016/j.foreco.2009.01.050, 2009.

Beguería, S.: Validation and Evaluation of Predictive Models in Hazard Assessment and Risk Management, Nat. Hazards, 37, 315-329, https://doi.org/10.1007/s11069-005-5182-6, 2006.

Blanchet, J., Marty, C., and Lehning, M.: Extreme value statistics of snowfall in the Swiss Alpine region, Water Resour. Res., 45, W05424, https://doi.org/10.1029/2009wr007916, 2009.

Blaschke, T.: Object based image analysis for remote sensing, ISPRS J. Photogramm., 65, 2-16, https://doi.org/10.1016/j.isprsjprs.2009.06.004, 2010.

Bocchiola, D., Bianchi Janetti, E., Gorni, E., Marty, C., and Sovilla, B.: Regional evaluation of three day snow depth for avalanche 
hazard mapping in Switzerland, Nat. Hazards Earth Syst. Sci., 8, 685-705, https://doi.org/10.5194/nhess-8-685-2008, 2008.

Budimir, M. E. A., Atkinson, P. M., and Lewis, H. G.: A systematic review of landslide probability mapping using logistic regression, Landslides, 12, 419-436, https://doi.org/10.1007/s10346014-0550-5, 2015.

Bühler, Y. and von Rickenbach, D.: Automated Avalanche Release Area (PRA) Delineation Davos, EnviDat, https://doi.org/10.16904/envidat.55, 2018.

Bühler, Y., Hüni, A., Christen, M., Meister, R., and Kellenberger, T.: Automated detection and mapping of avalanche deposits using airborne optical remote sensing data, Cold Reg. Sci. Technol., 57, 99-106, https://doi.org/10.1016/j.coldregions.2009.02.007, 2009.

Bühler, Y., Christen, M., Kowalski, J., and Bartelt, P.: Sensitivity of snow avalanche simulations to digital elevation model quality and resolution, Ann. Glaciol., 52, 72-80, https://doi.org/10.3189/172756411797252121, 2011.

Bühler, Y., Marty, M., and Ginzler, C.: High Resolution DEM Generation in High-Alpine Terrain Using Airborne Remote Sensing Techniques, T. Gis, 16, 635-647, https://doi.org/10.1111/j.14679671.2012.01331.x, 2012.

Bühler, Y., Kumar, S., Veitinger, J., Christen, M., Stoffel, A., and Snehmani: Automated identification of potential snow avalanche release areas based on digital elevation models, Nat. Hazards Earth Syst. Sci., 13, 1321-1335, https://doi.org/10.5194/nhess13-1321-2013, 2013.

Burrough, P. and McDonnell, R. A.: Principles of Geographical Information Systems, Oxford University Press, London, 330, https://doi.org/10.2307/144481, 1998.

Carrara, A.: Multivariate models for landslide hazard evaluation, Math. Geol., 15, 403-426, 1983.

Carrara, A. and Guzetti, F.: Geographical Information Systems in Assessing Natural Hazards, Springer, the Netherlands, 356 pp., https://doi.org/10.1007/978-94-015-8404-3, 1995.

Christen, M., Kowalski, J., and Bartelt, P.: RAMMS: Numerical simulation of dense snow avalanches in threedimensional terrain, Cold Reg. Sci. Technol., 63, 1-14, https://doi.org/10.1016/j.coldregions.2010.04.005, 2010.

Chueca Cía, J., Andrés, A. J., and Montañés Magallón, A.: A proposal for avalanche susceptibility mapping in the Pyrenees using GIS: the Formigal-Peyreget area (Sheet 145-I; scale 1:25.000), J. Maps, 10, 203-210, https://doi.org/10.1080/17445647.2013.870501, 2014.

Congalton, R. and Green, K.: Assessing the Accuracy of Remotely Sensed Data: Principles and Practices, Lewis Publishers, New York, 1999.

Eckerstorfer, M., Bühler, Y., Frauenfelder, R., and Malnes, E.: Remote sensing of snow avalanches: Recent advances, potential, and limitations, Cold Reg. Sci. Technol., 121, 126-140, https://doi.org/10.1016/j.coldregions.2015.11.001, 2016.

Eckerstorfer, M., Malnes, E., and Müller, K.: A complete snow avalanche activity record from a Norwegian forecasting region using Sentinel-1 satellite-radar data, Cold Reg. Sci. Technol., 144, 39-51, https://doi.org/10.1016/j.coldregions.2017.08.004, 2017.

Fonstad, M. A., Dietrich, J. T., Courville, B. C., Jensen, J. L., and Carbonneau, P. E.: Topographic structure from motion: a new development in photogrammetric measurement, Earth Surf. Proc. Land., 38, 421-430, https://doi.org/10.1002/esp.3366, 2013.

Frattini, P., Crosta, G., and Carrara, A.: Techniques for evaluating the performance of landslide susceptibility models, Eng. Geol., 111, 62-72, https://doi.org/10.1016/j.enggeo.2009.12.004, 2010.

Gariano, S. L., Brunetti, M. T., Iovine, G., Melillo, M., Peruccacci, S., Terranova, O., Vennari, C., and Guzzetti, F.: Calibration and validation of rainfall thresholds for shallow landslide forecasting in Sicily, southern Italy, Geomorphology, 228, 653-665, https://doi.org/10.1016/j.geomorph.2014.10.019, 2015.

Ghinoi, A. and Chung, C. J.: STARTER: A statistical GIS-based model for the prediction of snow avalanche susceptibility using terrain features - application to Alta Val Badia, Italian Dolomites, Geomorphology, 66, 305-325, 2005.

Gruber, S., Huggel, C., and Pike, R.: Modelling Mass Movements and Landslide Susceptibility, in: GEOMORPHOMETRY Concepts, Software, Applications, 2009.

Gruber, U. and Baltensweiler, A.: SilvaProtect-CH, Eidg. Forschungsanstalt WSL, Birmensdorf, Schweiz, 40, 2004.

Gruber, U. and Margreth, S.: Winter 1999: a valuable test of the avalanche-hazard mapping procedure in Switzerland, Ann. Glaciol., 32, 328-332, 2001.

Hanssen, A. W. and Kuipers, W. J. A.: On the Relationship Between the Frequency of Rain and Various Meteorological Parameters: (with Reference to the Problem of Objective Forecasting), Staatsdrukerij-en Uitgeverijbedrijf, the Hague, 1965.

Heidke, P.: Berechnung des Erfolges und der Güte der Windstärkevorhersagen im Sturmwarnungsdienst, Geogr. A., 8, 301349, https://doi.org/10.2307/519729, 1926.

Korzeniowska, K., Bühler, Y., Marty, M., and Korup, O.: Regional snow-avalanche detection using object-based image analysis of near-infrared aerial imagery, Nat. Hazards Earth Syst. Sci., 17, 1823-1836, https://doi.org/10.5194/nhess-17-1823-2017, 2017.

Lato, M. J., Frauenfelder, R., and Bühler, Y.: Automated detection of snow avalanche deposits: segmentation and classification of optical remote sensing imagery, Nat. Hazards Earth Syst. Sci., 12, 2893-2906, https://doi.org/10.5194/nhess12-2893-2012, 2012.

Leonarduzzi, E., Molnar, P., and McArdell, B. W.: Predictive performance of rainfall thresholds for shallow landslides in Switzerland from gridded daily data, Water Resour. Res., 53, 6612-6625, https://doi.org/10.1002/2017WR021044, 2017.

Maggioni, M.: Avalanche Release Areas and Their Influence on Uncertainty in Avalanche Hazard Mapping, University of Zurich UZH, Zurich, 2005.

Maggioni, M. and Gruber, U.: The influence of topographic parameters on avalanche release dimension and frequency, Cold Reg. Sci. Technol., 37, 407-419, https://doi.org/10.1016/S0165232X(03)00080-6, 2003.

Maggioni, M., Gruber, U., and Stoffel, A.: Definition and characterisation of potential avalanche release areas, ESRI International User Conference, San Diego, US, 2002, 1161-1166, 2002.

McClung, D. M.: Characteristics of terrain, snow supply and forest cover for avalanche initiation caused by logging, Ann. Glaciol. 32, 223-229, 2001.

Michoud, C., Derron, M.-H., Horton, P., Jaboyedoff, M., Baillifard, F.-J., Loye, A., Nicolet, P., Pedrazzini, A., and Queyrel, A.: Rockfall hazard and risk assessments along roads at a regional 
scale: example in Swiss Alps, Nat. Hazards Earth Syst. Sci., 12, 615-629, https://doi.org/10.5194/nhess-12-615-2012, 2012.

Pistocchi, A. and Notarnicola, C.: Data-driven mapping of avalanche release areas: A case study in South Tyrol, Italy, Nat. Hazards, 65, 1313-1330, https://doi.org/10.1007/s11069012-0410-3, 2013

Pradhan, B. and Buchroithner, M.: Terrigenous Mass Movements - Detection, Modelling, Early Warning and Mitigation using Geoinformation Technology, Springer-Verlag, Berlin, Heidelberg, 400 pp., https://doi.org/10.1007/978-3-642-25495-6, 2012.

Purves, R. S., Morrison, K. W., Moss, G., and Wright, D. S. B.: Nearest neighbours for avalanche forecasting in Scotland - development, verification and optimisation of a model, Cold Reg. Sci. Technol., 37, 343-355, https://doi.org/10.1016/S0165232X(03)00075-2, 2003.

Rudolf-Miklau, F., Sauermoser, S., and Mears, A.: The Technical Avalanche Protection Handbook, Wiley-VCH, Berlin, Germany, 2014.

Salm, B., Burkhard, A., and Gubler, H. U.: Berechnung von Fliesslawinen. Eine Anleitung für den Praktiker mit Beispielen, Eidgenössisches Institut für Schnee- und Lawinenforschung SLF, Davos, 1990.

Sampl, P. and Zwinger, T.: Avalanche simulation with SAMOS, Ann. Glaciol., 38, 393-398, 2004.

Sappington, J. M., Longshore, K. M., and Thompson, D. B.: Quantifying landscape ruggedness for animal habitat analysis: A case study using bighorn sheep in the Mojave Desert, J. Wildlife Manage., 71, 1419-1426, https://doi.org/10.2193/2005-723, 2007.

Schmudlach, G. and Köhler, J.: Method for an automatized avalanche terrain classification, International Snow Science Workshop, Breckenridge, CO, USA, 2016.

Schüepp, M. and Urfer, C.: Die Windverhältnisse im Davoser Hochtal, Arch. Meteor. Geophy. B, 12, 337-349, https://doi.org/10.1007/bf02315994, 1962.

Schweizer, J., Jamieson, J. B., and Schneebeli, M.: Snow avalanche formation, Rev. Geophys., 41, 2-1-2-25, https://doi.org/10.1029/2002RG000123, 2003.

Singh, L. P., van Westen, C. J., Ray, P. K. C., and Pasquali, P.: Accuracy assessment of InSAR derived input maps for landslide susceptibility analysis: A case study from the Swiss Alps, Landslides, 2, 221-228, https://doi.org/10.1007/s10346-005-0059-z, 2005.

SLF: Der Lawinenwinter 1999, Eidgenössisches Institut für Schnee- und Lawinenforschung, Davos, 2000.

Stehman, S. V. and Wickham, J. D.: Pixels, blocks of pixels, and polygons: Choosing a spatial unit for thematic accuracy assessment, Remote Sens. Environ., 115, 3044-3055, https://doi.org/10.1016/j.rse.2011.06.007, 2011.

swisstopo: swissALTI3D - Das hoch aufgelöste Terrainmodell der Schweiz, Swiss Federal Office of Topography swisstopo, Berne, Switzerland, 27, 2018.
Techel, F., Zweifel, B., and Winkler, K.: Analysis of avalanche risk factors in backcountry terrain based on usage frequency and accident data in Switzerland, Nat. Hazards Earth Syst. Sci., 15, 19851997, https://doi.org/10.5194/nhess-15-1985-2015, 2015.

van Herwijnen, A. and Heierli, J.: Measurement of crack-face friction in collapsed weak snow layers, Geophys. Res. Lett., 36, 1-5, https://doi.org/10.1029/2009GL040389, 2009.

Van Herwijnen, A., Gaume, J., Bair, E. H., Reuter, B., Birkeland, K. W., and Schweizer, J.: Estimating the effective elastic modulus and specific fracture energy of snowpack layers from field experiments, J. Glaciol., 62, 997-1007, https://doi.org/10.1017/jog.2016.90, 2016.

van Westen, C. J., Rengers, N., and Soeters, R.: Use of Geomorphological Information in Indirect Landslide Susceptibility Assessment, Nat. Hazards, 30, 399-419, https://doi.org/10.1023/B:NHAZ.0000007097.42735.9e, 2003.

van Westen, C. J., Castellanos, E., and Kuriakose, S. L.: Spatial data for landslide susceptibility, hazard, and vulnerability assessment: An overview, Eng. Geol., 102, 112-131, https://doi.org/10.1016/j.enggeo.2008.03.010, 2008.

Veitinger, J. and Sovilla, B.: Linking snow depth to avalanche release area size: measurements from the Vallée de la Sionne field site, Nat. Hazards Earth Syst. Sci., 16, 1953-1965, https://doi.org/10.5194/nhess-16-1953-2016, 2016.

Veitinger, J., Purves, R. S., and Sovilla, B.: Potential slab avalanche release area identification from estimated winter terrain: a multiscale, fuzzy logic approach, Nat. Hazards Earth Syst. Sci., 16, 2211-2225, https://doi.org/10.5194/nhess-16-2211-2016, 2016.

Vera Valero, C., Wever, N., Bühler, Y., Stoffel, L., Margreth, S., and Bartelt, P.: Modelling wet snow avalanche runout to assess road safety at a high-altitude mine in the central Andes, Nat. Hazards Earth Syst. Sci., 16, 2303-2323, https://doi.org/10.5194/nhess16-2303-2016, 2016.

Voellmy, A.: Über die Zerstörungskraft von Lawinen, Schweizerische Bauzeitung, 73, 159-165, 1955.

Vontobel, I.: Geländeanalysen von Unfalllawinen, MS, Department of Geography, University of Zurich, 89 pp., 2011.

Waser, L., Fischer, C., Wang, Z., and Ginzler, C.: Wall-to-Wall Forest Mapping Based on Digital Surface Models from Image-Based Point Clouds and a NFI Forest Definition, Forests, 6, 4510-4528, https://doi.org/10.3390/f6124386, 2015.

Wirz, V., Schirmer, M., Gruber, S., and Lehning, M.: Spatiotemporal measurements and analysis of snow depth in a rock face, The Cryosphere, 5, 893-905, https://doi.org/10.5194/tc-5893-2011, 2011 